\title{
ANALISIS UPAYA PEMASARAN (MARKETING EFFORTS) BERDASARKAN SEGMENTASI PASAR DARI ASPEK GENDER TABUNGAN BRITAMA PADA PT. BANK RAKYAT INDONESIA (Persero) Tbk KANTOR CABANG METRO
}

\section{An Analysis of Marketing Efforts Based on The Gender Aspect Market Segmentation of B ritama Savings At Pt. Bank Rakyat Indonesia (Limited) Tbk of Metro Branch Office}

\author{
Melan Susanty Purnamasari, S.E., M.M. \\ Administrasi Niaga, Universitas Tulang Bawang - Lampung \\ Email: meilan.susanty@gmail.com
}

\begin{abstract}
The economic crisis has made a lot of banks find difficulty in maintaining the customers to have always made use of banking service. It's suggested that marketing efforts which could understand the customers desire more need to be made so that the relation between the bank and the customers would increase and it will contribute to the profit.

The result of analysis shows that for female, the variables of price marketing mix $\left(X_{2}\right)$, employees $\left(X_{5}\right)$, and process $\left(X_{6}\right)$ are significantly influenced the length of savings time, while the variables of product $\left(X_{1}\right)$, promotion $\left(X_{3}\right)$, place $\left(X_{4}\right)$, and physical infrastructure $\left(X_{7}\right)$ are not significant. On the other hand, for male, only two variables, i.e. employees $\left(X_{5}\right)$ and process $\left(X_{6}\right)$ show significant influenced to the length of saving time while the variables of product $\left(X_{1}\right)$, price $\left(X_{2}\right)$, promotion $\left(X_{3}\right)$, place $\left(X_{4}\right)$, and physical infrastructure $\left(X_{7}\right)$ are not significant.
\end{abstract}

Keyword: Marketing Efforts, Market Segmentation.

\begin{abstract}
ABSTRAK
Sejak terjadinya krisis ekonomi menyebabkan banyak bank mengalami kesulitan mempertahankan nasabah untuk selalu menggunakan layanan bank. Oleh karena itu diperlukan upaya pemasaran (marketing efforts) yang lebih memahami keinginan nasabah, sehingga hubungan bank dengan nasabah meningkatkan pertumbuhan yang memberi kontribusi pada peningkatan laba.

Berdasarakan analisis regresi diperoleh hasil bahwa untuk aspek gender perempuan, atribut bauran pemasaran harga $\left(\mathrm{X}_{2}\right)$, karyawan $\left(\mathrm{X}_{5}\right)$, dan proses $\left(\mathrm{X}_{6}\right)$ secara statistik berpengaruh signifikan lamanya menabung sedangkan variabel produk $\left(\mathrm{X}_{1}\right)$, promosi $\left(\mathrm{X}_{3}\right)$, tempat $\left(\mathrm{X}_{4}\right)$ dan sarana fisik $\left(\mathrm{X}_{7}\right)$ tidak berpengaruh signifikan. Lain halnya dengan aspek gender laki-laki hanya dua atribut yang berpengaruh nyata yaitu karyawan $\left(\mathrm{X}_{5}\right)$ dan proses $\left(\mathrm{X}_{6}\right)$ sedangkan variabel produk $\left(\mathrm{X}_{1}\right)$, harga $\left(\mathrm{X}_{2}\right)$, promosi $\left(\mathrm{X}_{3}\right)$, tempat $\left(\mathrm{X}_{4}\right)$ dan sarana fisik $\left(\mathrm{X}_{7}\right)$ tidak berpengaruh signifikan.
\end{abstract}

Kata kunci: Upaya pemasaran, segmentasi pasar. 


\section{PENDAHULUAN}

\section{Latar Belakang}

Memasuki era persaingan yang semakin kompetitif dan terjadinya intensitas persaingan berskala global serta meningkatnya kepekaan masyarakat terhadap produk dan jasa sebuah bank, membuat bank milik pemerintah tidak bisa lagi mempertahankan kebijakan proteksi. Apalagi kebijakan pemerintah setelah terjadi krisis ekonomi tahun 1997, yaitu dengan melakukan penggabungan (merger) bahkan berupa pencabutan izin usaha, melakukan pembekuan kegiatan bank serta mengambil alih bank (take over)

Fenomena tersebut membuat bank beroperasi dalam pasar yang mengikuti Teori Darwin, yaitu prinsip seleksi alamiah yang mengarah kepada yang terkuat yang bertahan. Dalam situasi yang demikian sulit, bank masih tetap gencar menggali dan menghimpun dana dari masyarakat dalam rangka menjaga likuditas, fenomena ini terlihat dari agresivitas bank dalam menawarkan produk simpanannya kepada masyarakat.

Usaha perbankan adalah usaha kepercayaan baik kepercayaan dari kreditur, nasabah selaku pemilik dana maupun kepercayaan yang dipegang dan ditaati oleh para debitur selaku pengguna dana. Kepercayaan dari kreditur atau nasabah tidak akan datang begitu saja, tetapi melalui upaya komitmen yang selalu dipegang oleh perbankan. Komitmen diberikan melalui layanan yang cepat, akurat, aman dan mudah.

Strategi layanan yang diberikan perbankan sangat berpengaruh terhadap kepercayaan, citra (image), sebagai bukti lapangan dapat dilihat saat ini terutama bank-bank swasta yang mampu memberikan layanan di berbagai aspek sehingga menimbulkan citra yang baik. Setelah citra didapatkan, dana akan masuk dengan sendirinya. Dana yang masuk memberikan peluang kepada perbankan untuk memanfaatkannya di dalam aktiva produktif untuk mencapai profit yang maksimal.

Berbagai macam produk dan jasa yang ditawarkan oleh dunia perbankan yang melebihi kelebihan dan daya tarik tertentu dalam rangka memahami karakteristik dan perilaku konsumennya agar dapat bertahan hidup dan mampu bersaing dengan pesaingnya dalam memperebutkan pangsa pasar yang beragam dan luas cakupannya, membuat pemasar mengelompokkan pasar yang heterogen ke dalam kelompok atau segmen pasar ke arah homogen agar lebih mudah melayani konsumen. Perusahaan harus mengidentifikasi segmen pasar yang paling menarik supaya dapat dilayani dengan lebih efektif. (Kotler, 2003 : 278). Dengan kata lain agar lebih spesifik lagi bisa dilihat dari jenis kelamin atau gender, agar selanjutnya dapat ditentukan upaya pemasaran yang relevan dan memenuhi selera masing-masing segmen gender.

Bank Rakyat Indonesia sebagai bank tertua di Indonesia terus berupaya mempertahankan eksistensinya di tengah perubahan dan persaingan produk perbankan yang semakin beragam dengan berbagai macam hadiah yang menggiurkan. Untuk mengantisipasi berbagai persaingan tersebut pada tahun 1999, PT. Bank Rakyat Indonesia (BRI) mengeluarkan produk yang diberi nama Britama. Pemasaran produk Tabungan Britama ini merupakan jawaban dari tuntutan pasar. Kecepatan dan ketetapan merespon pasar tersebut sesuai dengan pendapat Davidow (2003), kebenaran hakiki dari pemasaran adalah untuk memenangkan persaingan harus menggunakan strategi dengan sukses atau berhasil, sebab pasar tidak bisa menunggu dengan sabar. Keputusan pemasaran yang dilakukan harus dengan tepat berdasarkan strategi. Perusahaan yang sukses adalah yang mengikuti prinsip strategi pemasaran yaitu pemasaran harus menciptakan produk yang lengkap dan membangkitkan 
permintaan dari segmen pasar yang ditetapkan.

Britama merupakan produk tabungan dari $\mathrm{BRI}$ pertama yang dapat bertransaksi tarik setor antar cabang (online), dan dapat mengambil uang tunai dari Anjungan Tunai Mandiri (ATM) dari bank lain. Pada awal peluncuran Britama tersebut, segmen pasar yang hendak dituju adalah orang dewasa, progressive, kelas sosial menengah ke atas dan pengunaan jasa bank lebih sebagai aktivitas kegiatan keuangan nasabah. Perluasan pasar ini memberikan tantangan bagi BRI untuk menyediakan fasilitas dan sistem yang lebih baik, mutu kecepatan dan ketepatan pelayanan yang lebih tinggi dari sumber daya manusia (SDM) BRI yang lebih profesional. Adanya penambahan produk BRI tersebut agar dapat diperoleh pergeseran citra (image) terhadap segmen pasar yang dituju.

Britama sebagai salah satu produk PT. Bank Rakyat Indonesia akan dijadikan objek dalam penelitian ini. Dalam situasi persaingan antar produk sejenis yang tajam akan tetapi peluang pasarnya pun masih terbuka luas, maka diperlukan segmensegmen pasar untuk menempatkan posisi produk Tabungan Britama. Pada penelitian ini akan digunakan dasar segmentasi gender yang dianggap sangat relevan untuk melakukan segmentasi pasar produk tabungan, serta melakukan analisis regresi untuk mengetahui variabel-variabel bauran pemasaran yang berpengaruh terhadap keputusan menabung konsumen guna merumuskan strategi pemasaran yang tepat berdasarkan segmentasi, targeting dan positioning bagi segmen yang dilayani. Dengan melakukan segmentasi pasar, diharapkan pada akhirnya produk BRI Britama dapat menyusun suatu bauran pemasaran (marketing mix) yang tepat dengan segmentasi pasarnya.

\section{Perumusan Masalah}

Berdasarkan uraian pada latar belakang, dapat diidentifikasi masalah dalam penelitian ini sebagai berikut:

1. Sejauh mana pengaruh segmentasi pasar berdasarkan gender terhadap lamanya menabung agar selanjutnya dapat ditentukan upaya pemasaran (marketing efforts) melalui bauran pemasaran yang relevan dan memenuhi selera masing-masing segmen gender pada Tabungan Britama.

2. Bauran pemasaran mana saja yang akan

berpengaruh nyata terhadap segmentasi pasar Tabungan Britama.

\section{Tujuan Penelitian}

Penelitian yang dilakukan pada nasabah penabung Britama ini bertujuan:

1. Untuk mengetahui sejauh mana pengaruh segmentasi pasar berdasarkan gender terhadap lamanya menabung pada Tabungan Britama, dan untuk menentukan upaya pemasaran (marketing efforts) melalui bauran pemasaran yang relevan pada masing-masing segmen gender pada Tabungan Britama.

2. Untuk mengetahui bauran pemasaran mana saja yang akan berpengaruh terhadap segmentasi pasar Tabungan Britama.

\section{Manfaat Penelitian}

Hasil penelitian ini berguna untuk:

1. Dapat lebih meningkatkan penghimpunan dana dan jumlah penabung Britama serta memberikan sumbangan pemikiran bagi manajemen untuk pengembangan lebih lanjut produk Britama dan strategi pemasaran selanjutnya, setelah diketahui segmen pasarnya.

2. Bagi peneliti, sebagai pengalaman penelitian yang dapat dipergunakan dalam melaksanakan pekerjaan atau penelitian lainnya. 
3. Penelitian lanjutan, sebagai bahan informasi untuk memperdalam dan memperluas faktor keberhasilan dalam segmentasi baik lembaga perbankan maupun perusahaan lainnya.

\section{Hipotesis}

Berdasarkan latar belakang dan kerangka pemikiran, dapat ditetapkan hipotesis sebagai berikut:

Segmentasi pasar dari aspek gender dipengaruhi oleh upaya pemasaran (marketing efforts) Tabungan Britama pada PT. Bank Rakyat Indoneisa (Persero) Tbk Kantor Cabang Metro.

\section{Pemasaran Jasa}

Menurut Zeithaml dan Bitner (1996:23), terdapat dua konsep bauran pemasaran yaitu bauran tradisional (produk, harga, tempat dan promosi atau yang lebih dikenal dengan 4-P), konsep kedua yaitu bauran pemasaran jasa yaitu konsep pertama ditambah people, physical e--vidence, process (7-P).

Secara umum beberapa analisis mengemukakan bahwa jasa merupakan suatu aktivitas, manfaat atau kepuasan yang ditawarkan untuk dijual. Kotler (2003:444) memberikan definisi: jasa merupakan setiap tindakan atau perbuatan yang dapat ditawarkan oleh suatu pihak kepada pihak lain dan pada dasarnya bersifat tidak terwujud (intangible) dan tidak menghasilkan kepemilikan sesuatu apapun, meskipun demikian, produksinya dapat dikaitkan pada suatu produk secara fisik.

\section{Karakteristik Jasa}

Ditinjau dari rancangan yang mempengaruhi program pemasarannya, jasa atau layanan memiliki empat karakteristik utama (Kotler, 2003: 446-449), yaitu:

1. Intangibility. Jasa merupakan hal yang tidak nyata, tidak dapat dilihat dicoba, dirasakan, dan didengar sebelum membelinya oleh nasabah.
2. Inseparability. Jasa merupakan proses produksi yang bersamaan waktunya dengan saat konsumsi atau pemakaian nasabah.

3. Variabilty. Unsur Jasa terdiri dari banyak variasi atau beragam.

4. Perishability. Jasa bersifat sirna dan tidak bisa disimpan atau dijual kembali.

\section{Penentuan Segmen Pasar (Market Segmentation)}

Segmentasi pasar adalah suatu konsep yang sangat penting dalam kehidupan ini, bukan hanya untuk kepentingan bisnis tetapi juga untuk kegiatan-kegiatan kemasyarakatan atau kegiatan-kegiatan nirlaba lainnya. Dalam kegiatan bisnis segmentasi pasar digunakan untuk memilih pasar sasaran, mencari peluang, menggerogoti segmen pemimpin pasar, merumuskan pesan-pesan komunikasi, melayani lebih baik, ,menaganalisis perilaku konsumen, mendesain produk, dan lain sebagainya.

Diperlukan untuk mengukur daya tarik serta segmen yang perlu dimasuki untuk mengevaluasi segmen yang harus diperhatikan adalah:

1. Ukuran dan pertumbuhan segmen

2. Daya tarik struktural segmen

\section{Arti Penting Segmentasi}

Analisis segmentasi perlu dilakukan karena perilaku konsumen sangat beragam, untuk itu perlu dilakukan segmentasi pasar yaitu membagi pasar menjadi lebih homogen, hingga relatif mempunyai kebutuhan dan keinginan yang sama. Jadi segmentasi adalah tindakan mengelompokkan tanggapan yang sama dari konsumen terhadap program pemasaran perusahaan (Irawan, 2001).

Ada beberapa keuntungan dengan melakukan segmentasi ini:

1. Dapat mendeteksi perubahan trend pasar yang berubah cepat

2. Desain produk sungguh-sungguh memenuhi permintaan konsumen 
3. Dapat menentukan usaha pemasaran yang lebih efektif

4. Menentukan kuantitas promosi yang tepat pada media yang tepat, dan bagi segmen yang potensial

5. Menjadwalkan promosi pada periode yang tepat sesuai dengan waktu responsiveness yang paling tinggi.

Bersamaan dengan keuntungan yang timbul dalam penggunaan metode segmentasi, ada kerugian yang muncul yaitu besarnya biaya. Misalnya biaya riset dan promosi yang lebih tinggi . Selain itu juga timbul kemungkinan adanya kanibalisme jika perusahaan melayani beberapa segmen yang dekat.

\section{Metode Segmentasi}

Menurut Haley (1991), pada mulanya segmentasi dilakukan dengan metode yang paling sederhana yaitu dengan mensegmenkan konsumen berdasarkan letak geografis mereka.

Makin cangginnya distribusi peusahaan tertentu dan meluasnya skala usaha mendorong muculnya metode segmentasi lain yaitu berdasarkan demografi.

Metode yang ketiga adalah metode volume segmentation. Metode ini menganggap bahwa secara logis suatu perusahaan harus memusatkan perhatian pada konsumen yang membentuk bagian terbesar dari penjualan perusahaan.

\section{Langkah-langkah Segmentasi}

Melakukan

1. Identifikasi masalah atau tentukan kegunaan riset yang ingin dihasilkan.

2. Seleksi Basis Segmentasi.

3. Pilih descriptor variable yang dapat mendefinisikan basis segmentasi.

4. Membentuk sampel yang representatif untuk dianalisis.

5. Mengumpulkan data dari sampel tersebut.

6. Membentuk segmen berdasarkan descriptor yang telah dipilih.

7. Membentuk profil segmen.
8. Menerjemahkan hasilnya dalam marketing strategy.

\section{Penggunaan Studi Segmentasi}

Tujuan utama dari studi segmentasi adalah untuk menyediakan landasan pengenalan konsumen yang sangat dibutuhkan perusahaan agarb produk diterima oleh konsumen.

Strategi Segmentasi Differensiasi menawarkan berbagai produk kepada beberapa segmen. Bank dapat dikatakan menganut strategi ini dengan banyaknya penawaran produk yang mereka lakukan bagi bermacam-macam tipe konsumen, dari yang memberikan kredit perumahan bagi pasangan muda, maupun yang menawarkan executive membership bagi kalangan high level income.

Dari hasil analisis upaya pemasaran Tabungan Britama PT. BRI Kantor Cabang Metro akan diketahui perilaku gender terhadap upaya pemasaran yang dilakukan. Pengembangan strategi pemasaran (Segmentation, Targeting, Positioning, STP) selanjutnya diarahkan pada strategi segmentasi gender melalui program bauran pemasaran. Dengan demikian implementasi strategi diprioritaskan pada upaya bauran pemasaran pada segmentasi gender dengan memperhatikan karaktersitik serta perilaku masing-masing gender.

\section{METODE PENELITIAN}

\section{Desain Pengambilan Sampel}

Sampel yang digunakan dalam penelitian ini adalah berasal dari kerangka pengambilan sampel (sampling frame) berupa database pelanggan (daftar anggota populasi). Metode atau teknik pengambilan sampel menggunakan estimasi proporsi mengacu kepada pendapat Slovin (Umar, 2003: 146) dengan rumus sebagai berikut:

$n=\frac{N}{1+\mathrm{Ne}^{2}}$

Keterangan: 


$$
\begin{aligned}
\mathrm{n}= & \text { ukuran sampel } \\
\mathrm{N}= & \text { ukuran populasi } \\
\mathrm{e} \quad \text { prosentase } & \text { kelongggaran } \\
& \text { ketidaktelitian karena kesalahan } \\
& \text { pengambilan sampel yang masih } \\
& \text { dapat ditolerir atau dinginkan }
\end{aligned}
$$

Melalui penyulihan berbagai angka tersebut diatas ke dalam persamaan, dengan asumsi galat baku sebesar 10\%, menghasilkan besaran sampel sebagai berikut:

$$
\begin{aligned}
& n=\frac{10.265}{1+10.265 \times 0.1^{2}} \\
& n=99
\end{aligned}
$$

Dengan demikian besarnya sampel adalah 99 orang.

Teknik pengambilan sampel digunakan syarat sampel yaitu:

1. Penabung Britama PT. BRI Kantor Cabang Metro yang nilai tabungannya lebih besar dari tabungan Britama yang dipersyaratkan minimum dan merupakan penabung yang aktif.

2. Nasabah yang betransaksi pada hari kerja pada PT. BRI Kantor Cabang Metro. Dengan sampel diambil acak di tempat (on the spot sampling) pada tanggal 3 sampai dengan 12 Februari 2005, sampai terkumpul 99 orang responden.

\section{Variabel Penelitian}

Variabel dalam penelitian ini adalah: indenpenden $(\mathrm{X})$ adalah tingkat motivasi dalam penentuan segmen melalui bauran

\begin{tabular}{|c|c|c|c|c|}
\hline $\begin{array}{l}\text { Varia } \\
\text { bel }\end{array}$ & $\begin{array}{l}\text { Konsep } \\
\text { Variabel }\end{array}$ & $\begin{array}{l}\text { Indikator } \\
\text { Variabel }\end{array}$ & $\begin{array}{l}\text { Ukuran } \\
\text { Variabel }\end{array}$ & $\begin{array}{l}\text { Skala } \\
\text { Data }\end{array}$ \\
\hline $\begin{array}{l}\text { Produ } \\
\mathrm{k}\left(\mathrm{X}_{1}\right)\end{array}$ & $\begin{array}{l}\text { Produk } \\
\text { yang } \\
\text { ditawarkan: } \\
\text { Pengetahuan } \\
\text {,manfaat,kea } \\
\text { ndalan } \\
\text { produk }\end{array}$ & $\begin{array}{l}\text { Kesesuaian } \\
\text { bauran } \\
\text { produk } \\
\text { dengan } \\
\text { kebutuhan } \\
\text { pasar } \\
\text { sasaran }\end{array}$ & $\begin{array}{l}\text { Tingkat } \\
\text { kesesua } \\
\text { ian } \\
\text { bauran } \\
\text { produk }\end{array}$ & $\begin{array}{l}\text { Ordin } \\
\text { al }\end{array}$ \\
\hline $\begin{array}{l}\text { Harga } \\
\left(X_{2}\right)\end{array}$ & $\begin{array}{l}\text { Penentua } \\
\mathrm{n} \text { harga } \\
\text { beli } \\
\text { produk } \\
\text { (suku } \\
\text { bunga) }\end{array}$ & $\begin{array}{l}\text { Kesesuaia } \\
\mathrm{n} \text { bauran } \\
\text { harga beli } \\
\text { (suku } \\
\text { bunga) } \\
\text { dengan } \\
\text { kemampu } \\
\text { an pasar } \\
\text { sasaran }\end{array}$ & $\begin{array}{l}\text { Tingkat } \\
\text { kesesua } \\
\text { ian } \\
\text { harga } \\
\text { beli } \\
\text { (suku } \\
\text { bunga) }\end{array}$ & $\begin{array}{l}\text { Ordin } \\
\text { al }\end{array}$ \\
\hline $\begin{array}{l}\text { Prom } \\
\text { osi } \\
\left(X_{3}\right)\end{array}$ & $\begin{array}{l}\text { Penentua } \\
\mathrm{n} \\
\text { kombinasi } \\
\text { dari alat } \\
\text { promosi } \\
\text { yang } \\
\text { digunakan } \\
\text { untuk } \\
\text { mencapai } \\
\text { sasaran }\end{array}$ & $\begin{array}{l}\text { Kesesuaia } \\
\mathrm{n} \text { promosi } \\
\text { dengan } \\
\text { karakterist } \\
\text { ik pasar } \\
\text { sasaran }\end{array}$ & $\begin{array}{l}\text { Tingkat } \\
\text { kesesua } \\
\text { ian } \\
\text { produk }\end{array}$ & $\begin{array}{l}\text { Ordin } \\
\text { al }\end{array}$ \\
\hline $\begin{array}{l}\text { Temp } \\
\text { at } \\
\left(\mathrm{X}_{4}\right)\end{array}$ & $\begin{array}{l}\text { Keunggula } \\
\mathrm{n} \text { lokasi } \\
\text { sebagai } \\
\text { tempat } \\
\text { penyalura } \\
\mathrm{n} \text { produk } \\
\text { dan } \\
\text { pelayanan } \\
\text { kepada } \\
\text { nasabah }\end{array}$ & $\begin{array}{l}\text { Kesesuaia } \\
\mathrm{n} \text { dalam } \\
\text { memilih } \\
\text { jalur } \\
\text { sasaran }\end{array}$ & $\begin{array}{l}\text { Tingkat } \\
\text { kesesua } \\
\text { ian jalur } \\
\text { sasaran }\end{array}$ & $\begin{array}{l}\text { Ordin } \\
\text { al }\end{array}$ \\
\hline $\begin{array}{l}\text { Karya } \\
\text { wan } \\
\left(X_{5}\right)\end{array}$ & $\begin{array}{l}\text { Kemampu } \\
\text { an, } \\
\text { kualitas } \\
\text { dan } \\
\text { ketersedia } \\
\text { an SDM } \\
\text { untuk } \\
\text { pemasara } \\
\text { n }\end{array}$ & $\begin{array}{l}\text { Kesesuaia } \\
\mathrm{n} \\
\text { kemampu } \\
\text { an, } \\
\text { kualitas } \\
\text { dan } \\
\text { ketersedia } \\
\text { an SDM }\end{array}$ & $\begin{array}{l}\text { Tingkat } \\
\text { kesesua } \\
\text { ian jalur } \\
\text { sasarn }\end{array}$ & $\begin{array}{l}\text { Ordin } \\
\text { al }\end{array}$ \\
\hline $\begin{array}{l}\text { Prose } \\
\mathrm{s}\left(\mathrm{X}_{6}\right)\end{array}$ & $\begin{array}{l}\text { Ketepatan } \\
\text { dan } \\
\text { kecepatan } \\
\text { layanan }\end{array}$ & $\begin{array}{l}\text { Keseusaia } \\
\mathrm{n} \quad \text { waktu } \\
\text { layanan }\end{array}$ & $\begin{array}{l}\text { Tingkat } \\
\text { kesesua } \\
\text { ian } \\
\text { waktu } \\
\text { layanan }\end{array}$ & $\begin{array}{l}\text { Ordin } \\
\text { al }\end{array}$ \\
\hline $\begin{array}{l}\text { Saran } \\
\text { a } \\
\text { Fisik } \\
\left(X_{7}\right)\end{array}$ & $\begin{array}{l}\text { Penampila } \\
\mathrm{n} \text {, } \\
\text { penataan } \\
\text { kantor }\end{array}$ & $\begin{array}{l}\text { Kesesuaia } \\
\mathrm{n} \\
\text { penampila } \\
\mathrm{n} \text {, } \\
\text { penataan } \\
\text { kantor }\end{array}$ & $\begin{array}{l}\text { Tingkat } \\
\text { kesesua } \\
\text { ian } \\
\text { penamp } \\
\text { ilan } \\
\text { penataa } \\
\mathrm{n} \text { kantor }\end{array}$ & $\begin{array}{l}\text { Ordin } \\
\text { al }\end{array}$ \\
\hline
\end{tabular}
pemasaran yang terdiri dari produk, harga, promosi, tempat, karyawan, proses dan sarana fisik. Sedangkan variabel dependen (Y) adalah lamanya menabung yang dinyatakan dalam bulan.

Variabel penelitian, definisi variabel, indikator ukuran dan skala pengukuran dapat dijelaskan seperti pada tabel berikut: 


\begin{tabular}{|l|l|l|l|l|}
\hline Lama & Kesetiaan & Lamanya & $\begin{array}{l}\text { Tingkat } \\
\text { nya }\end{array}$ & $\begin{array}{l}\text { Ordin } \\
\text { konsumen }\end{array}$ \\
mena & pada & mensumen \\
bung & produk & & al \\
tabunga & \\
di & yang & & $n$ & \\
Tab. & ditawarka & & & \\
Brita & $\mathrm{n}$ & & & \\
ma & & & & \\
$(\mathrm{Y})$ & & & & \\
\hline
\end{tabular}

Sumber: Data diolah, 2005

\section{Skala Pengukuran Variabel}

Variabel yang diteliti, dihitung dengan pemberian skor dari masing-masing jawaban pada daftar pertanyaan yang telah disusun, dengan menyusun Skala Likert untuk mengukur model sikap. Setiap pertanyaan memuat 5 alternatif jawaban berdasarkan jenjang tertentu dari tertinggi sampai terendah.

Untuk memperoleh hasil jawaban kuesioner yang lebih signifikan, maka setiap jawaban diberikan interval penilaian, sebagai berikut:
a. Sangat setuju, interval penilaiannya antara 81 sampai dengan 100
b. Setuju, interval penilaiannya antara 61 sampai dengan 80
c. Cukup Setuju, interval penilaiaannya antara 41 sampai dengan 60
d. Kurang Setuju, interval penilaiannya antara 21 sampai dengan 40
e. Sangat Tidak Setuju, interval penilaiannya antara 0 sampai dengan 20

\section{Metode Pengumpulan Data}

Metode pegumpulan data yang digunakan dalam penelitian dengan cara sebagai berikut:

a. Kuesioner

Daftar pertanyaan yang dibuat dalam bentuk sederhana dengan metode pertanyaan dipersiapkan sebelumnya dan kemudian diberikan kepada responden untuk dijawab. Responden tersebut adalah penabung Britama pada PT. BRI Kantor Cabang Metro..

b. Wawancara

Sebagai teknik komunikasi langsung untuk memperoleh data yang diperlukan yang terkait dengan produk Tabungan Britama.

c. Teknik kepustakaan

Mencari data yang berkaitan dengan bidang yang diteliti.

\section{Uji Validitas dan Reliabilitas Kuesioner}

Untuk mengetahui tingkat relevansi skala dalam mengukur suatu konstruk maka perlu dilakukan pengujian terhadap instrumen atau kuesioner yang digunakan dengan cara uji validitas dan reliabilitas. Dengan uji validitas dapat diketahui sejauh mana suatu alat pengukur itu mampu mengukur apa yang ingin diukur. Sedangkan dengan uji reliabilitas, dapat diketahui suatu angka indeks yang menunjukkan konsistensi suatu alat gejala yang sama.

Uji validitas akan dibatasi pada penyusunan skala sikap dengan validitas kontruk. Untuk mengukur validitas konstruk digunakan langkah-langkah sebagai berikut: (Umar. H, 2003: 189)

1. Mengidentifikasi secara operasional konsep yang akan diukur pada kuesioner.

2. Melakukan uji coba pengukur tersebut pada sejumlah responden (minimal 30 orang).

3. Mempersiapkan tabel tabulasi jawaban.

4. Menghitung korelasi antara masingmasing pernyataan dengan skor total memakai rumus teknik korelasi product moment yang dikemukakan oleh Pearson.

Jika misalnya nilai korelasi $(r)$ sebesar 0,2557 maka $r=0,065$, artinya hanya $6,5 \%$ saja hasil pengukuran yang sebenarnya dan $93,5 \%$ terjadi kesalahan pengukuran (Bangsawan dan Nusyirwan, 2003: 8).

Uji indeks reliabilitas dengan menggunakan teknik Spearman-Brown, yaitu:

$$
r_{11}=\frac{2 r_{12}}{1+r_{12}}
$$


Keterangan:

$r_{11}=$ indeks reliabilitas

$\mathrm{r}_{12}=$ korelasi product moment antar dua kelompok

Teknik ini berkehendak untuk menguji reliabilitas pertanyaan-pertanyaan atau pernyataan-pernyataan yang berbentuk skala, yang mempunyai hubungan satu sama lain.

Jika misalnya indeks reliabiltas SpearmanBrown sebesar 0,4072 lebih kecil dibandingkan dengan tabel harga $r$ product moment dengan taraf kepercayaan 95\% dan $n=10$ yaitu 0,632, artinya kuesioner tidak reliabel dijadikan alat ukur untuk mencapai tujuan penelitian. (Bangsawan dan Nusyirwan, 2003 : 2-8).

\section{Metode Analisis Data}

Data yang diperoleh melalui pengisian daftar pertanyaan akan dikumpulkan, diolah, dan dianalisis dengan menggunakan rumus analisis Regresi Berganda, demgan rumus sebagai berikut:

1. $Y_{L}=a+b_{1} X_{1}+b_{2} X_{2}+b_{3} X_{3}+b_{4} X_{4}+$

$$
b_{5} X_{5}+b_{6} X_{6}+b_{7} X_{7}+E t
$$

$$
\begin{gathered}
Y_{P}=a+b_{1} X_{1}+b_{2} X_{2}+b_{3} X_{3}+b_{4} X_{4}+ \\
b_{5} X_{5}+b_{6} X_{6}+b_{7} X_{7}+E t
\end{gathered}
$$

Keterangan:

$\mathrm{Y}=$ Hasil upaya pemasaran (marketing efforts) yang dinyatakan dengan lamanya nasabah menabung pada Tabungan Britama PT. BRI Kantor Cabang Metro

$\mathrm{X}_{1}=$ Produk

$\mathrm{X}_{2}=$ Harga

$\mathrm{X}_{3}=$ Promosi

$\mathrm{X}_{4}=$ Tempat

$\mathrm{X}_{5}=$ Karyawan

$\mathrm{X}_{6}=$ Proses

$\mathrm{X}_{7}=$ Sarana Fisik

$\mathrm{a}=$ Tetapan

$b_{1}, b_{2}, b_{3}, b_{4}, b_{5}, b_{6}, b_{7}=$ Koefisien regresi

$E_{t}=$ Galat baku

\section{HASIL DAN PEMBAHASAN}

\section{Uji Validitas dan Reliabilitas}

Hasil pengujian reliabilitas dan validitas dari daftar pertanyaan yang digunakan, dengan menggunakan rumus korelasi product moment Pearson dan indeks reliabilitas Spearman-Brown diperoleh hasil seperti ditunjukkan dalam tabel 4.1 berikut ini:

Tabel 4.1 Pengukuran Validitas Alat Ukur

\begin{tabular}{|l|l|c|l|}
\hline No & \multicolumn{1}{|c|}{ Variabel } & $\begin{array}{c}\text { Nilai } \\
\text { Korelasi }\end{array}$ & $\begin{array}{c}\text { Signifikan } \\
\text { si }\end{array}$ \\
\hline 1 & Produk $\left(\mathrm{X}_{1}\right)$ & 0,851 & Signifikan \\
\hline 2 & Harga $\left(\mathrm{X}_{2}\right)$ & 0,561 & Signifikan \\
\hline 3 & $\begin{array}{l}\text { Promosi } \\
\left(\mathrm{X}_{3}\right)\end{array}$ & 0,687 & Signifikan \\
\hline 4 & Tempat $\left(\mathrm{X}_{4}\right)$ & 0,697 & Signifikan \\
\hline 5 & $\begin{array}{l}\text { Karyawan } \\
\left(\mathrm{X}_{5}\right)\end{array}$ & 0,973 & Signifikan \\
\hline 6 & Proses $\left(\mathrm{X}_{6}\right)$ & 0,866 & Signifikan \\
\hline 7 & $\begin{array}{l}\text { Sarana fisik } \\
\left(\mathrm{X}_{7}\right)\end{array}$ & 0,712 & Signifikan \\
\hline
\end{tabular}

Dari Tabel 4.1 tampak bahwa semua item mempunyai nilai yang signifikan, dengan kata lain pertanyaan atau pernyataan tiap variabel pada kuesioner valid digunakan dalam kuesioner. Juga diperoleh nilai korelasi product moment 0,8061 atau indeks reliabilitas Spearman_Brown ) 0,8927 . Bila dibandingkan dengan nilai $t_{\text {tabel }}$ product moment 0,514 (taraf kepercayaan $95 \%$ dan $n$ Split half $=15$ ), maka dengan demikian pertanyaan atau pernyataan tiap variabel dalam kuesioner tersebut handal reliabel untuk dijadikan alat ukur dalam penelitian.

\section{Analisis Statistik Regresi Berganda}

Analisis data secara kuantitatif dilakukan melalui pendekatan statistik yaitu dengan Model analisis regresi berganda digunakan untuk mengetahui pengaruh peubah bebas Produk $\left(X_{1}\right)$, Harga $\left(X_{2}\right)$, Promosi $\left(X_{3}\right)$, Tempat $\left(X_{4}\right)$, Karyawan $\left(X_{5}\right)$, Proses $\left(X_{6}\right)$, Sarana Fisik $\left(X_{7}\right)$ terhadap peubah terikat yaitu lamanya menabung $(Y)$ pada $\mathrm{PT}$. BRI Kantor Cabang Metro.

Berdasarkan hasil olahan pada kuesioner, pada gender perempuan diperoleh nilai 
rerata variabel $\left(\mathrm{Y}_{\mathrm{P}}=36\right)$, dengan simpangan baku $=9$, dengan demikian maka dapat ditentukan skala intervalnya yaitu:

$56-65$ bulan $=5$
$46-55$ bulan $=4$
$36-45$ bulan $=3$
$26-35$ bulan $=2$
$16-25$ bulan $=1$

Sedangkan pada gender laki-laki dapat ditentukan skala intervalnya diperoleh rerata variabel pada $\left(Y_{L}=33\right)$ dan simpangan baku $=7$, sebagai berikut:

$49-56$ bulan $=5$

$41-48$ bulan $=4$

$33-40$ bulan $=3$

$25-32$ bulan $=2$

$17-24$ bulan $=1$

Hasil perhitungan dengan menggunakan komputer Program SPSS 11.0 berdasarkan pengolahan data maka diperoleh hasil dalam bentuk persamaan regresi yang dapat ditulis hasil persamaan regresi berganda sebagai berikut:

Regresi berganda untuk gender Perempuan:

$\mathrm{Y}_{\mathrm{P}}=-0,687+0,0011 \mathrm{X}_{1}+0,0086 \mathrm{X}_{2}-0,0008 \mathrm{X}_{3}$ $+0,00006 X_{4}+0,0083 X_{5}+0,0031 X_{6}$ $+0,00011 X_{7}$

\begin{tabular}{lccrr} 
Se & $(0,001)$ & $(0,002)$ & $(0,001)$ & \\
& $(0,001)$ & $(0,002)$ & $(0,001)$ & $(0,001)$ \\
$\mathrm{t}$ & 1,264 & 5,423 & $-0,756$ & \\
& 0,058 & 3,823 & 2,622 & \\
& 0,124 & & & \\
\multicolumn{4}{c}{$\mathrm{R}^{2}=$} & 0,970 \\
\multicolumn{7}{r}{$\mathrm{F}_{\text {hitung }}=$} & 198,237
\end{tabular}

Regresi berganda untuk gender Laki-laki: $Y_{L}=-2,033+0,0006 X_{1}+0,0013 X_{2}-0,0004 X_{3}$ $-0,0002 X_{4}+0,0124 X_{5}+0,0121 X_{6}$ $+0,0033 X_{7}$

$\begin{array}{cccc}\text { Se } & (0,004) & (0,002) & (0,004) \\ & (0,004) & (0,003) & (0,003)(0,004) \\ \mathrm{T} & 0,166 & 0,536 & 0,111 \\ & -0,046 & 3,605 & 4,830 \\ & 0,812 & & \end{array}$

$R^{2}=0,859$

$F_{\text {hitung }}=34,794$

Keterangan:

$\mathrm{Y}=$ Lamanya Menabung yang dinyatakan dalam bulan

$\mathrm{X}_{1}=$ Produk

$\mathrm{X}_{2}=$ Harga

$\mathrm{X}_{3}=$ Promosi

$\mathrm{X}_{4}=$ Tempat

$\mathrm{X}_{5}=$ Karyawan

$\mathrm{X}_{6}=$ Proses

$\mathrm{X}_{7}=$ Sarana Fisik

\section{Uji Hipotesis}

\section{Pengujian Keberartian secara Keseluruhan (Uji-F)}

Pengujian keberartian pengaruh peubah bebas pada masing-masing gender secara keseluruhan terhadap variabel terikat digunakan Uji Fisher (Uji F) dengan tingkat kepercayaan $95 \%$ atau alpha sebesar 0,05. Pada gender perempuan, $\mathrm{df}_{1 \mathrm{p}}=\mathrm{k}-1=8-1=$ $7, \mathrm{df}_{2} \mathrm{n}-\mathrm{k}=51-8=43$, dan gender lakilaki, $\mathrm{df}_{1 \mathrm{~L}}=\mathrm{k}-1=8-1=7, \mathrm{df}_{2} \mathrm{n}-\mathrm{k}=48-8=$ 40, dengan ketentuan:

$\mathrm{H}_{0}: \mathrm{b}_{1}=0$, tidak berpengaruh nyata

$H_{0}: b_{1} \neq 0$, berpengaruh nyata

Apabila $F_{\text {hitung }}<F_{\text {tabel }}$ berarti hipotesis nol $\left(\mathrm{H}_{0}\right)$ diterima dan hipotesis alternatif $\left(\mathrm{H}_{\mathrm{a}}\right)$ ditolak. Apabila $F_{\text {hitung }}>F_{\text {tabel }}$ berarti hipotesis nol $\left(\mathrm{H}_{0}\right)$ ditolak dan hipotesis alternatif $\left(\mathrm{H}_{\mathrm{a}}\right)$ diterima.

Dari perhitungan dengan menggunakan SPSS, pada gender perempuan diperoleh Nilai $F_{\text {hitung }}=198,237$. Dengan menggunakan Tabel Distribusi $F$ pada tingkat kepercayaan $95 \%(\alpha=0,05), \mathrm{df}_{1 \mathrm{P}}=$ $7, \mathrm{df}_{2 \mathrm{P}}=43$, diperoleh $\mathrm{F}_{\text {tabel }}=2,25$. Keberartian regresi tersebut dapat dilihat pada tabel berikut.

\footnotetext{
Tabel 4.2 Keberartian Hubungan Peubah Terikat Secara Keseluruhan Pada Gender Perempuan dengan $(\alpha=0,05), \quad\left(d f_{1 P}\right)=7$ $\operatorname{dan}\left(d f_{2 P}\right)=43$
} 


\begin{tabular}{|c|c|c|}
\hline$F_{\text {hitung }}$ & $\mathrm{F}_{0,05 ; 7 ; 43}$ & Simpulan \\
\hline 198,237 & 2,25 & $\mathrm{H}_{0}$ ditolak \\
\hline
\end{tabular}

Karena $F_{\text {hitung }}>\mathrm{F}_{\text {tabel }}$ maka $\mathrm{H}_{0}$ ditolak dan $\mathrm{H}_{\mathrm{a}}$ diterima, ini berarti secara statistik semua variabel $\left(X_{1}, X_{2}, X_{3}, X_{4}, X_{5}, X_{6}\right.$ dan $X_{7}$ ) secara keseluruhan atau bersamasama berpengaruh nyata terhadap variabel bebas (Y) sebesar 97\% pada tingkat kepercayaan $95 \%$. Sisanya 3\% dipengaruhi oleh faktor-faktor lain yang tidak diteliti.

Pada Gender Laki-laki diperoleh Nilai $F_{\text {hitung }}$ $=34,794$. Dengan menggunakan Tabel Distribusi $F$ pada tingkat kepercayaan $95 \%=(\alpha=0,05), \quad \mathrm{df}_{1 \mathrm{~L}}=7, \mathrm{df}_{2 \mathrm{~L}}=40$, diperoleh $F_{\text {tabel }}=2,25$.

Keberartian regresi tersebut dapat dilihat pada tabel berikut.

Tabel 4.3 Keberartian Hubungan Peubah Bebas terhadap Peubah Terikat Secara Keseluruhan Pada Gender Laki-laki dengan $(\alpha=0,05)$, $\left(d f_{1 L}\right)=7$ dan $\left(d f_{2 L}\right)=40$

\begin{tabular}{|c|c|c|}
\hline $\mathrm{F}_{\text {hitung }}$ & $\mathrm{F}_{0,05 ; 7 ; 40}$ & Simpulan \\
\hline 34,794 & 2,25 & $\mathrm{H}_{0}$ ditolak \\
\hline
\end{tabular}

Karena $F_{\text {hitung }}>F_{\text {tabel }}$ maka $\mathrm{H}_{0}$ ditolak dan $\mathrm{H}_{\mathrm{a}}$ diterima, ini berarti secara statistik semua variabel $\left(X_{1}, X_{2}, X_{3}, X_{4}, X_{5}, X_{6}\right.$ dan $\left.X_{7}\right)$ secara keseluruhan atau bersamasama berpengaruh nyata terhadap variabel bebas (Y) sebesar 85,9\% pada tingkat kepercayaan $\quad 95 \%$. Sisanya 4,1\% dipengaruhi oleh faktor-faktor lain yang tidak diteliti.

\section{Pengujian Keberartian Secara Parsial (Uji t)}

Pengujian Hipotesis masing-masing peubah bebas dengan menggunakan uji $t$ (uji student) yang dimaksudkan untuk menguji keterkaitan masing-masing variabel bebas terhadap variabel terikat secara parsial pada tingkat kepercayaan 95\% atau alpha sebesar 0,05 dengan derajat kebebasan $(\mathrm{dk})=\mathrm{n}-\mathrm{k}-1=99-7-1=9$, dengan ketantuan:

$\mathrm{H}_{0}: \mathrm{b}_{\mathrm{i}}=0$, tidak terdapat keterkaitan antara variabel $\mathrm{X}$ dan $\mathrm{Y}$.

$H_{a}: b_{i}=0$, terdapat keterkaitan antara variabel $\mathrm{X}$ dan $\mathrm{Y}$.

Apabila diperoleh thitung positif maka berlaku:

$t_{\text {hitung }} \leq \mathrm{t}_{\text {tabel }}$, maka $\mathrm{H}_{0}$ diterima

$t_{\text {hitung }}>\mathrm{t}_{\text {tabel}}$, maka $\mathrm{H}_{0}$ ditolak

Apabila diperoleh thitung negatif maka berlaku:

$t_{\text {hitung }} \leq \mathrm{t}_{\text {tabel, }}$, maka $\mathrm{H}_{0}$ diterima

$t_{\text {hitung }}>t_{\text {tabel, }}$, maka $\mathrm{H}_{0}$ ditolak

Berdasarkan hasil perhitungan, maka hasil pengujian untuk gender perempuan dapat dilihat pada Tabel 4.5 berikut:

\section{Tabel 4.4 Hasil Pengujian Hipotesis Gender Perempuan dengan Menggunakan Uji t}

\begin{tabular}{|l|l|l|l|l|}
\hline No & $\begin{array}{l}\text { Variabel } \\
\text { Bebas } \\
\text { (Perempu } \\
\text { an) }\end{array}$ & $\begin{array}{l}\mathbf{t}- \\
\text { hitun } \\
\mathbf{g}\end{array}$ & $\begin{array}{l}\text { Nilai } \\
\mathbf{T}_{0,05}\end{array}$ & $\begin{array}{l}\text { Kesi } \\
\text { mpula } \\
\mathbf{n}\end{array}$ \\
\hline 1 & $\begin{array}{l}\text { Produk } \\
\left(\mathrm{X}_{1}\right)\end{array}$ & 1,264 & 1,645 & $\begin{array}{l}\mathrm{H}_{0} \\
\text { diteri } \\
\text { ma }\end{array}$ \\
\hline 2 & Harga $\left(\mathrm{X}_{2}\right)$ & 5,423 & 1,645 & $\begin{array}{l}\mathrm{H}_{0} \\
\text { ditolak }\end{array}$ \\
\hline 3 & $\begin{array}{l}\text { Promosi } \\
\left(\mathrm{X}_{3}\right)\end{array}$ & $-0,756$ & $-1,645$ & $\begin{array}{l}\mathrm{H}_{0} \\
\text { diteri } \\
\text { ma }\end{array}$ \\
\hline 4 & $\begin{array}{l}\text { Tempat } \\
\left(\mathrm{X}_{4}\right)\end{array}$ & 0,058 & 1,645 & $\begin{array}{l}\mathrm{H}_{0} \\
\text { diteri } \\
\text { ma }\end{array}$ \\
\hline 5 & $\begin{array}{l}\text { Karyawan } \\
\left(\mathrm{X}_{5}\right)\end{array}$ & 3,823 & 1,645 & $\begin{array}{l}\mathrm{H}_{0} \\
\text { ditolak }\end{array}$ \\
\hline 6 & $\begin{array}{l}\text { Proses } \\
\left(\mathrm{X}_{6}\right)\end{array}$ & 2,622 & 1,645 & $\begin{array}{l}\mathrm{H}_{0} \\
\text { ditolak }\end{array}$ \\
\hline 7 & $\begin{array}{l}\text { Sarana } \\
\text { Fisik }\left(\mathrm{X}_{7}\right)\end{array}$ & 0,124 & 1,645 & $\begin{array}{l}\mathrm{H}_{0} \\
\text { diteri } \\
\text { ma }\end{array}$ \\
\hline
\end{tabular}

Secara statistik berdasarkan Uji-t, nilai thitung untuk variabel bebas harga $\left(X_{2}\right)$, karyawan $\left(X_{5}\right)$ dan proses $\left(X_{6}\right)$ lebih besar angka mutlak dibandingkan dengan nilai $t_{\text {tabel }}$ pada 
alpha 0,05 dan derajat kebebasan sebesar 43 yang berarti masing-masing variabel bebas yaitu harga $\left(X_{2}\right)$, karyawan $\left(X_{5}\right)$, proses $\left(X_{6}\right)$, mempengaruhi secara nyata terhadap upaya pemasaran produk Britama pada PT. BRI Kantor Cabang Metro.

Hasil pengujian untuk gender laki-laki dapat dilihat pada Tabel 4.6 di bawah ini .

Tabel 4.5 Hasil Pengujian Hipotesis Gender Laki-laki dengan Menggunakan Uji t

\begin{tabular}{|l|l|l|l|l|}
\hline No & $\begin{array}{l}\text { Variabel } \\
\text { Bebas } \\
\text { (Perempu } \\
\text { an) }\end{array}$ & $\begin{array}{l}\text { t- } \\
\text { hitun } \\
\mathbf{g}\end{array}$ & $\begin{array}{l}\text { Nilai } \\
\mathbf{T}_{0,05}\end{array}$ & $\begin{array}{l}\text { Kesi } \\
\text { mpula } \\
\mathbf{n}\end{array}$ \\
\hline 1 & $\begin{array}{l}\text { Produk } \\
\left(\mathrm{X}_{1}\right)\end{array}$ & 0,166 & 1,645 & $\begin{array}{l}\mathrm{H}_{0} \\
\text { diteri } \\
\text { ma }\end{array}$ \\
\hline 2 & Harga $\left(\mathrm{X}_{2}\right)$ & 0,536 & 1,645 & $\begin{array}{l}\mathrm{H}_{0} \\
\text { diteri } \\
\text { ma }\end{array}$ \\
\hline 3 & $\begin{array}{l}\text { Promosi } \\
\left(\mathrm{X}_{3}\right)\end{array}$ & 0,111 & 1,645 & $\begin{array}{l}\mathrm{H}_{0} \\
\text { diteri } \\
\text { ma }\end{array}$ \\
\hline 4 & $\begin{array}{l}\text { Tempat } \\
\left(\mathrm{X}_{4}\right)\end{array}$ & $-0,046$ & $-1,645$ & $\begin{array}{l}\mathrm{H}_{0} \\
\text { diteri } \\
\text { ma }\end{array}$ \\
\hline 5 & $\begin{array}{l}\text { Karyawan } \\
\left(\mathrm{X}_{5}\right)\end{array}$ & 3,605 & 1,645 & $\begin{array}{l}\mathrm{H}_{0} \\
\text { ditolak }\end{array}$ \\
\hline 6 & $\begin{array}{l}\text { Proses } \\
\left(\mathrm{X}_{6}\right)\end{array}$ & 4,830 & 1,645 & $\begin{array}{l}\mathrm{H}_{0} \\
\text { ditolak }\end{array}$ \\
\hline 7 & $\begin{array}{l}\text { Sarana } \\
\text { Fisik }\left(\mathrm{X}_{7}\right)\end{array}$ & 0,812 & 1,645 & $\begin{array}{l}\mathrm{H}_{0} \\
\text { diteri } \\
\text { ma }\end{array}$ \\
\hline
\end{tabular}

Secara statistik berdasarkan Uji-t, nilai thitung untuk variabel bebas karyawan $\left(X_{5}\right)$ dan proses $\left(X_{6}\right)$ lebih besar angka mutlak dibandingkan dengan nilai $t_{\text {tabel }}$ pada alpha 0,05 dan derajat kebebasan sebesar 40 yang berarti masing-masing variabel bebas yaitu karyawan $\left(X_{5}\right)$, proses $\left(X_{6}\right)$, mempengaruhi secara nyata terhadap upaya pemasaran produk Britama pada PT. BRI Kantor Cabang Metro.

\section{Implikasi Hasil Perhitungan}

Pembahasan hasil perhtungan terhadap tujuh vari.abel bebas $(X)$ berupa variabel bauran pemasaran dan satu variabel terikat berupa lamanya menabung (Y). Bagi gender perempuan terdapat tiga variabel yang berpengaruh nyata terhadap lamanya menabung, yaitu harga $\left(X_{2}\right)$, karyawan $\left(X_{5}\right)$ dan proses $\left(X_{6}\right)$ pada tingkat kepercayaan $95 \%$. Sedangkan bagi gender laki-laki terdapat dua variabel yang berpengaruh nyata terhadap lamanya menabung, yaitu karyawan $\left(\mathrm{X}_{5}\right)$ dan proses $\left(\mathrm{X}_{6}\right)$ pada tingkat kepercayaan $95 \%$. Untuk variabel lainnya tidak berpengaruh nyata terhadap lamanya nasabah menabung yaitu produk $\left(X_{1}\right)$, promosi $\left(X_{3}\right)$, tempat $\left(X_{4}\right)$ dan sarana fisik $\left(X_{7}\right)$ bagi gender perempuan, sedangkan untuk gender laki-laki terdapat lima variabel yang tidak berpengaruh nyata yaitu produk $\left(X_{1}\right)$, harga $\left(X_{2}\right)$, promosi $\left(X_{3}\right)$, tempat $\left(X_{4}\right)$ dan sarana fisik $\left(X_{7}\right)$ pada tingkat kepercayaan $95 \%$.

\section{KESIMPULAN DAN SARAN}

\section{KESIMPULAN}

Program bauran pemasaran jasa yang meliputi harga/suku bunga $\left(X_{2}\right)$ untuk gender perempuan, dan bagi kedua gender variabel karyawan $\left(X_{5}\right)$ dan proses $\left(X_{6}\right)$, mempengaruhi secara nyata terhadap lamanya menabung ( $\mathrm{Y}$ ) pada $\mathrm{PT}$. Bank Rakyat Indonesia (Persero) Tbk Kantor Cabang Metro.

Faktor bauran pemasaran karyawan merupakan faktor yang signifikan dari kedua aspek gender, terhadap upaya peningkatan pemasaran produk Tabungan Britama, pengaruh yang terjadi disebabkan karena karyawan terutama teller dan customer service berinteraksi secara langsung dengan nasabah. Interaksi ini sangat mempengaruhi persepsi konsumen terhadap kualitas karyawan baik kepribadian maupun kemampuan dalam pelayanan kepada nasabah.

1. Faktor bauran pemasaran proses sangat berpengaruh signifikan dari kedua aspek gender, terhadap upaya peningkatan pemasaran produk Tabungan Britama, kemudahan dan 
kecepatan proses merupakan faktor yang sangat penting bagi nasabah, antara lain: proses pengajuan kredit, pelayanan transfer, transaksi tabungan dan lain-lain.

2. Variabel bauran pemasaran produk $\left(X_{1}\right)$, promosi $\left(X_{3}\right)$, tempat $\left(X_{4}\right)$ dan sarana fisik $\left(X_{7}\right)$ bagi gender perempuan dan bagi gender laki-laki variabel produk $\left(X_{1}\right)$, harga $\left(X_{2}\right)$, promosi $\left(X_{3}\right)$, tempat $\left(X_{4}\right)$ dan sarana fisik $\left(X_{7}\right)$ tidak berpengaruh nyata terhadap lamanya menabung (Y) pada PT. Bank Rakyat Indonesia (Persero) Tbk Kantor Cabang Metro.

\section{SARAN}

1. Untuk meningkatkan layanan, pada nasabah yang sensitif terhadap atribut harga khususnya gender perempuan, PT. Bank Rakyat Indonesia (Persero) Tbk Kantor Cabang Metro perlu melakukan pendekatan upaya pemasaran, seperti:

a. Memberi suku bunga yang kompetitif.

b. Memberi hadiah, baik langsung maupun bersifat undian.

c. Menciptakan suasana transaksi yang menyenangkan, seperti menyediakan koran, menyediakan mesin hitung uang secara gratis kepada nasabah, dan lain-lain.

2. Untuk menghadapi persaingan yang semakin ketat agar dapat mempertahankan nasabah yang telah ada dan dapat meningkatkan jumlah nasabah baru, perlu adanya peningkatan kualitas SDM (karyawan) agar memenuhi standar dan kualitas layanan yang diharapkan konsumen maka perlu adanya pemasaran internal (karywan dengan pimpinan), dan pemenuhan kebutuhan karyawan.

3. Untuk meningkatkan proses pelayanan perlu adanya sistem perbankan yandapat tercipta sehingga nasabah akan terpuaskan, seperti banking system yang mutakhir, jaringan ATM yang luas, Mesin Antri, Jaringan On-line dan lain-lain.

4. Agar upaya pemasaran (marketing efforts) Tabungan Britama PT. Bank Rakyat Indonesia (Persero) Tbk Kantor Cabang Metro, penelitian lebih lanjut dalam advokasi pelanggan, kolaborasi dengan mitra bisnis, profit chain, peningkatan mutu layanan internal (kepuasan karyawan dalam bekerja).

\section{DAFTAR PUSTAKA}

[1] Aaker, David A. 1991. Managing Brand Equity Capitalizing on The Value of Brand Name. The Free Press. New York.

[2] Anderson, Martin. 2003. "Networked Customer Activity Mapping", Babson Insight.

http://www.babsoninsight.com.March.

[3] Bangsawan, Satria dan Nusyirwan. 2003. Uji Reliabilitas dan Validitas Kuesioner dengan Aplikasi SPSS. Modul pada Program Studi Pascasarjana, Program Magister Manajemen Fakultas Ekonomi Universitas Lampung. Bandarlampung.

[4] Berry, Leonard L. dan A. Parasuraman. 1997. Listening to The Customer The Concept of $A$ Service-quality Information System. http://www.mit.smr.com. (Reprint 3835, Spring, Volume 38, Number 3)

[5] Churcill, Jr. Gilbert A., dan J. Paul Peter. 1998. Marketing Creating Value for Customers. Edisi kedua. Irwin/Mc Graw-Hill. Boston.

[6] Cooper, Donald R. dan Pamela S. Schindler, 2003. Business Research Methods. Edisi kedelapan. Irwin/Mc Graw-Hill. New York. 
[7] Cravens, David W. dan Nigel F. Piercy. 2003. Strategic Marketing. Edisi ketujuh. Mc Graw-Hill/Irwin. Boston. MA.

[8] Davidow, H. William. http://dcd marketing.com.

[9] Goncalves Karen P., 1998. Service Marketing: A Strategic Approach, New Jersey Prentice Hall. Inc

[10] Haley, Rusesel L. 1991, Benefit Segmentation A Decision Oriented Research Tool in B.M. Enis and K.K. Cox (eds), Marketing Classics A Selection of Influential Articles, edisi ketujuh. Boston, MA, Allyn and Bacon.

[11] Heskett, James L. Thomas O. Jones, Gary W. Loveman, W. Earl Sasser, Jr., and Leonard A. Schlesinger, 1994. Putting the service-profit chain to work. Business Classics: Fifteen Key Coccepts for Managerial Success 1998. Harvard Business Review's selected articles. Harvard Business School Publishing.

[12] Irawan, 2001, Pemasaran Prinsip dan Kasus. Edisi 2. Universitas Gadjah Mada. Yogyakarta.

[13] Kasali, Rhenald, 2001. Membidik Pasar Indonesia, Segmentasi, Targeting, dan Positioning. PT. Gramedia Pustaka Utama. Jakarta.

[14] Kotler, Philip, 2000. Marketing Management. Edisi Milenium, Prentice-Hall International Inc.

[15] Kotler, Philip, 2003. Marketing Management International Edition. Edisi kesebelas. Pearson Education Inc., Upper Saddle River, New Jersey.
[16] Law, Monica, Theresa Lau dan Y.H. Wong, 2003. From Customer Relationship Management to Customer Managed Relationship Unraveling the Paradox with a Cocreative Perpective. Marketing Intelligence \& Planning (21/1).

[17] Loundon, David dan A.J. Della Bitta, 1993. Customer Behaviour Concepts and Applications. Edisi 4. Mc GrawHill/New York.

[18] McDonald, Malcolm. 2002. "Market Segmentation", http://www.google.com.

[19] Piercy, Nigel F. 1995. What do you do to Get Customer Focus in an Organization? Marketing Intelligence \& Planning (Vol.13 No.6)

[20] Rangkuti, Freddy. 2000. Analisis SWOT Teknik Membedah Kasus Bisnis. PT. Gramedia Pustaka Utama, Jakarta.

[21] Rust. Roland T., Anthony J. Zahorik., Timothy L. Keiningham. 1996. Service Marketing. Edisi pertama. Harper Collins College Publishers, New York.

[22] Umar, Husein, 2003. Riset Pemasaran \& Perilaku Konsumen. PT. Gramedia Pustaka Utama, Jakarta.

[23] Urban, Glen., 2004. The Emerging Era of Customer Advocacy. MITSloan Management Review (Winter, Vol.45 No.2)

[24] Zeithaml, Valerie A., Mary Jo Bitner, 1996, Service Marketing, Edisi Pertama The McGraw-Hill Companies, Inc, Singapore. 